\title{
AC 2005-372: BIOTECHNOLOGY CURRICULUM FOR WORKFORCE DEVELOPMENT IN FLORIDA
}

\section{Edwin Goolsby,}

Linda Austin,

Marilyn Barger, Hillsborough Community College

Richard Gilbert,

Tomas Cavanagh, 


\title{
The Florida Consortium for Biotechnology Workforce Development
}

\author{
Marilyn Barger, Edwin Goolsby, Richard Gilbert, Thomas Cavanagh, Linda Austin \\ Hillsborough Community College/University of South Florida/Florida Space \\ Research Institute/Florida Community College at Jacksonville
}

\section{Background}

Florida's biotechnology industry is poised for rapid growth and development. Florida currently ranks second in the nation in biomedical employment with more than 2,000 firms employing 50,000 workers in manufacturing medical devices, producing ophthalmic goods, developing biomedical technologies, and discovering and producing new pharmaceuticals, vaccines and diagnostic tests. Most of the elements needed to support rapid expansion of this key industry sector are in place; however, one critical element still needed to support further biotechnology industry expansion in Florida is a highly skilled workforce. Workforce Florida, Inc.'s (WFI) February 2003 report on the biotechnology industry identified workforce development as key to improving Florida's ability to recruit and retain biotech companies. According to this report, the primary goal in workforce development should be to develop, “short-term, customized training curricula” that provides training in core skills needed for entry level jobs in the biotechnology industry, and address the needs of recent high school graduates, dislocated workers and individuals changing careers. WFI's 2003 report followed the October 2002 governor designation of the biomedical industry sector as a "high impact” sector. "High Impact” also signifies high wage, high skill job providers. In addition, these business sectors are eligible for state investment tax credits and performance incentives to biotechnology and pharmaceutical companies and medical device makers for expansion or relocation to Florida.

In the summer of 2003, Workforce Florida, Inc. awarded a \$1.2 million contract to Florida Community College at Jacksonville (FCCJ) and its partners from Florida academic institutions and industry to develop a comprehensive training curriculum for three biotechnology disciplines: biotechnology laboratory technology, biomanufacturing, and regulatory affairs. This new coalition of industry organizations, educational institutions, and other agencies, The Florida Consortium for Biotechnology Workforce Development, is chartered specifically to address one major issue; creating and sustaining a skilled biotechnology workforce.

The Consortium consists of:

- Three Florida community colleges - Florida Community College at Jacksonville (FCCJ), Santa Fe Community College (SFCC), and Hillsborough Community College (HCC)

- Three state research universities - the University of Florida (UF), Florida Atlantic University (FAU), and the University of South Florida (USF)

- BioFlorida, the state industry organization for biotechnology 
- The Florida Resource Center for Occupational Program Design and Evaluation, Daytona Beach Community College (DBCC)

- The Florida Space Research Institute (FSRI), co-manager of the Space Life Sciences Laboratory at the Kennedy Space Center and developer of the Advanced Learning Environment - the platform to be used for the web-based curriculum

- Steel Beach Productions, Inc., an experienced developer of web-based curriculum materials

The curriculum developed by the consortium is charged to be industry-driven and includes six community college level technical courses in Biotechnology and 40 hours of online self-paced modules. The online modules will be endorsed by the state's biotech industry sector and be appropriate for use within the biotechnology community college courses developed by the consortium. The web-based modules offer a rapid-response method to introduce the workforce at various levels (new graduates, incumbent workers, career transition, etc.) to the biotechnology industry and provide them with valuable real-world information that will better enable them to be immediately productive in their new job. In addition, because the modules can be incorporated into academic courses, they can serve as a bridge for workers to pursue further higher education. Ultimately, the online modules will be available throughout the state for workforce training and the community college curriculum will be available to colleges throughout the state that either have or want to develop a program in biotechnology disciplines.

\section{Curriculum Development - Focus Groups}

The Consortium began the curriculum development process by conducting focus groups throughout Florida to align the training goals with industry workforce needs. Three focus groups were held in Gainesville, Boca Raton, and Tampa to determine the skill sets that will serve as the focus for curriculum development. These locations were chosen for their high concentrations of biotechnology firms and for their designation as sites for regional committees of BioFlorida. The primary objective of the focus groups were to select specific skill sets and skills standards that are appropriate for inclusion in short-term training programs designed to quickly prepare individuals to enter the workforce. A matrix was used to establish and prioritize skill sets.

The agenda for each focus group included:

- Identification of local/regional job needs, including job titles and job descriptions

- Review of existing national skill standards in biotechnology

- Identification of required entry-level skills, suitable for short-term training programs

- Recommendations for training delivery methods and preferred training providers

Several key findings resulted from the meetings, including:

1. The biotechnology industry is very diverse and there isn't a single organization currently in place to provide a program endorsement. However, one could be created/established. It was generally agreed that, for the purposes of this project, the scope of the biotechnology industry should exclude hospitals and medically related clinical trials.

2. Entry-level biotechnology workers will need a broad knowledge base addressing a variety of topics. The group described a preference for a curriculum that is wider than it is deep. For example, an entry-level worker will need to have general safety knowledge and awareness, but much information is facility-specific and inappropriate for a general curriculum.

3. There seemed to be unanimous support for the notion that web-based instruction will be an important part of the eventual curriculum. Although it may not replace all hands-on 
training, the web based instruction can be instrumental in reducing lab time required for some entry-level skills which have traditionally been taught in a completely hands-on environment. Several samples of existing interactive ALE courseware were demonstrated to illustrate the potential of web-based instruction as an orientation to laboratory practices and there was a very positive response to it as both an orientation and review tool to provide consistent quality overviews and demonstrations of basic laboratory practices.

4. It may be appropriate for smaller specializations to branch off from a core curriculum of instruction. There was support for the concept of a general core of skills/competencies with specializations as appropriate (e.g., greenhouse technicians, animal care technicians, etc.).

5. A two-year degree was thought to be insufficient for a position in the field of Regulatory Affairs in the biotechnology industry. Participants generally classified this body of knowledge to be at the 4-year degree level or above. Most participants agreed that Quality Assurance and Quality Control could be suitable to the entry-level practitioner with a 2year degree, and that these skill categories could be expanded a little more to encompass some of the elementary aspects of Regulatory Affairs. Awareness of Regulatory compliance was considered important for all areas, including entry-level technicians.

\section{Curriculum Development - the Matrix}

A key objective for the focus group meetings was to quantify each skill on the matrix according to the Performance Criteria Analysis (PCAL) ${ }^{1}$ method. This method is a step-by-step technique for identifying the skills an individual needs to be successful in a particular job, and therefore, what a successful student will be able to do as a result of completing the training for that job. The matrix is constructed of several columns, including a column identifying each job skill and four blank PCAL columns: Importance, Level, Time and Difficulty. Industry attendees rated each skill in the matrix on a scale of 1 to 4, as follows:

Importance (How important is it for entry level employees to know or do the skill?)

4 = Highest: $\quad$ Much higher priority than other skills on the list.

3 = High: $\quad$ Somewhat higher priority than other skills on the list.

2 = Low: $\quad$ Somewhat lower priority than other skills on the list.

1 = Lowest: Much lower priority than other skills on the list.

Level (How good is good enough for entry level employees to know or do the skill?)

4 = Highest: Can recall and apply complex facts and principles and resolve problems.

3 = High: $\quad$ Can recall and apply many facts and principles to different situations.

2 = Low: $\quad$ Can recall some facts and principles. Can state general principles about the subject.

1 = Lowest: $\quad$ Can recognize only simple facts and terms.

Time (How frequently are entry level employees expected to know or do the skill?)

4 = Highest: Spends much more time doing this than most other skills on the list.

3 = High: $\quad$ Spends a little more time doing this than other skills on the list.

2 = Low: $\quad$ Spends somewhat less time doing this than other skills on the list.

$1=$ Lowest: $\quad$ Spends much less time doing this than other skills on the list.

Difficulty (How difficult is it for entry level employees to know or do the skill?)

4 = Highest: Much more difficult to learn and perform than other skills on the list.

3 = High: $\quad$ Somewhat more difficult to learn and perform than other skills on the list.

2 = Low: $\quad$ Somewhat easier to learn and perform than other skills on the list.

1 = Lowest: $\quad$ Much easier to learn and perform than other skills on the list. 
Quantification of the skills matrix provided an objective measurement of the relative importance of each skill.

With this kind of data, curriculum developers could make decisions about what should be in the curriculum, what should be emphasized, and how much time should be devoted to it in relation to other skills and knowledge. The curriculum development is being coordinated by the community colleges represented in the consortium. The university partners serve as curricular consultants, ensuring that the latest university-level research is included in the cutting-edge workforce training. Once developed, the curriculum documents are being converted into modular, interactive, webbased training offerings, compliant with Shareable Content Object Reference Model (SCORM) standards, by the Florida Space Research Institute for delivery via the existing Workforce Floridafunded Advanced Learning Environment (ALE).

\section{Curriculum Development - Design}

Curriculum writers utilized the matrix as an outline for curriculum module development and prepared material using a basic content development template. After each set of basic module content was complete, it went to Steel Beach for storyboarding (storyboards serve as a design script for programming and media production). After storyboarding, a Subject Matter Expert (SME), an authority independent from the original writer who is experienced in the topic, reviewed each module for technical accuracy and grammatical errors, documenting comments and edits in a standard report form. Following any revisions, the modules were then returned to Steel Beach to be produced as web-based modules. Once online, the modules would again be reviewed by the initial module writer and the independent SME, plus an editorial/functional reviewer for accuracy and functionality. The whole curriculum development and design process is captured in the flow sheet in Appendix 1.

\section{Curriculum Development - Beta Testing}

Following the development of the online modules, two phases of Beta Testing are being conducted. Each community college partner will offer the curriculum modules, including those developed for web-based delivery, to a population of students recruited specifically for this purpose during fall 2004 and spring 2005 terms. Beta test participants will be recruited from several key populations:

- students currently enrolled in related programs at the community colleges

- regional workforce board clients seeking employment or career change

- incumbent workers in biotechnology firms needing skills upgrading Evaluation data to be gathered as part of the beta test phase falls into two categories. Using Kirkpatrick's levels of evaluation, they would be classified as Level 1 and Level 2. ${ }^{2}$ Level 1 evaluation solicits student reaction to training and typically is conducted with questionnaires or interviews at the end of the training program. This type of data is used to determine whether the students consider the training relevant to their jobs and suited to their needs and learning styles. The ALE offers an online survey capability that auto-generates a compiled report of feedback results. Level 2 evaluation determines whether the students have mastered the specified performance objectives. Through the comparison of baseline pretest data with terminal posttest performance, the training validity can be assessed. These results should answer the questions: 
"Does the instruction properly teach the objectives? Did the students learn what was intended?" Embedded within the ALE is the capability to generate individual and aggregate student test performance results, including the capability to perform specific test item analysis. By reviewing student performance statistics, trends can be identified (e.g., all students miss a particular question on a particular test) and mitigation strategies can be implemented (e.g., revise the question if it is a poor question or revisit the training the content, if it was inadequate to prepare the learner for the test).

\title{
Biotechnology Symposium
}

In conjunction with the focus groups, a one-day national symposium on biotechnology education was held in Jacksonville, FL and hosted by FCCJ in November 2004. Representatives of community colleges and other training providers, who currently offer biotechnology education and training programs in other parts of the country, as well as members of national and regional industry groups, participated and shared their expertise and experience. This event helped communicate the statewide dialog being initiated in Florida and ensures that best practices in use elsewhere in the country are incorporated into the Florida curriculum and Consortium protocols. Attendees and speakers of the symposium included representatives from a state-wide Biotechnology Educational consortium in North Carolina, BioLink (a National Science Foundation National Center of Excellence for Biotechnology Curriculum in community colleges), and others.

\section{Summary}

The Florida Consortium for Biotechnology Workforce Development incorporates the business/industry, education, and technology partners needed to successfully produce high-quality, competency-based, industry-validated curriculum needed to build Florida's biotechnology workforce. The beta testing process will be completed by May 1, 2005 and the final web-based modular and community college degree curricula will be turned over to Workforce Florida in June 2005, for distribution throughout the state. The Consortium views this project as a significant step forward in addressing the biotechnology industry's critical workforce needs, and is positioned and prepared to continue the effort through further education, training, and dissemination initiatives. The Consortium also offers its framework for technical curriculum development as an efficient and effective model for curriculum development in other technical areas.

\author{
References \\ ${ }^{1}$ Performance Criteria Analysis (PCAL) is a registered title for a process developed by Richland College, Dallas, \\ Texas, to systematically identify skills that students need to be successful. \\ ${ }^{2}$ Kirkpatrick, D.L. (1994). Evaluating Training Programs: The Four Levels. San Francisco, CA: Berrett-Koehler.
}

\section{Authors}

MARILYN BARGER is the Executive Director of FL-ATE, the Florida Regional Center for Manufacturing Education housed at Hillsborough Community College. She earned a B.A. in Chemistry at Agnes Scott College, and both a B.S. in Engineering Science and a Ph.D. in Civil Engineering from the University of South Florida. She has over 15 years of experience in developing curriculum in engineering and engineering technology and is a registered professional engineer in the State of Florida. 
EDWIN GOOLSBY is one of three Instructional Program Managers for the Florida Consortium for Biotechnology Workforce Development representing Hillsborough Community College (HCC). Ed's responsibilities for the consortium include overseeing HCC's share of the curriculum development, module reviews and Beta Testing of the biotechnology program development. Ed holds a BS in Management Information Systems (MIS) from the University of South Florida (USF) and an MBA and MS in MIS from USF. He is also an adjunct instructor in Computer Science at HCC. Ed has served on the Baldridge Steering Committee and the District Advisory Board for HCC.

RICHARD GILBERT is a professor of Chemical Engineering at the University of South Florida.

THOMAS B. CAVANAGH is Program Manager for the Florida Space Research Institute at the Kennedy Space Center, where he oversees the institute's Advanced Learning Environment (ALE). Tom's work with the ALE has been featured in numerous publications including Training magazine, Federal Computer Week, Space News, Information Week, and the Washington Post. Tom holds a BS in Communications from the University of Miami, an MBA in Technology Management from the University of Phoenix in Orlando, and is pursuing a Ph.D. in Texts \& Technology at the University of Central Florida. He represents the Independent Colleges and Universities of Florida on the Florida Distance Learning Consortium and sits on the Advisory Board for the Brevard Community College Virtual Campus. He can be reached at 321-452-2653, ext. 211 or tcavanagh@fsri.org.

LINDA AUSTIN is the Executive Director of the Advanced Technology Center at FCCJ. The \$25 million ATC provides a technology-rich environment for the College's expanding program inventory in information technology, biotechnology, advanced manufacturing and transportation technology and provides area employers with an optimal employee training venue. Dr. Austin is responsible for leading the development and implementation of academic programs at the ATC as well as building strong business and industry training partnerships. She has extensive experience in higher education as an administrator, faculty member, and resource developer in the United States, Europe and Asia. She also has business experience in the fields of educational publishing, computer information systems and project management. Dr. Austin earned her EdD at the University of Houston, MS at the University of Tennessee, and BS at the University of West Florida. 
Session 3486

\section{Appendix 1. Biotechnology Curriculum Development Project Overview}

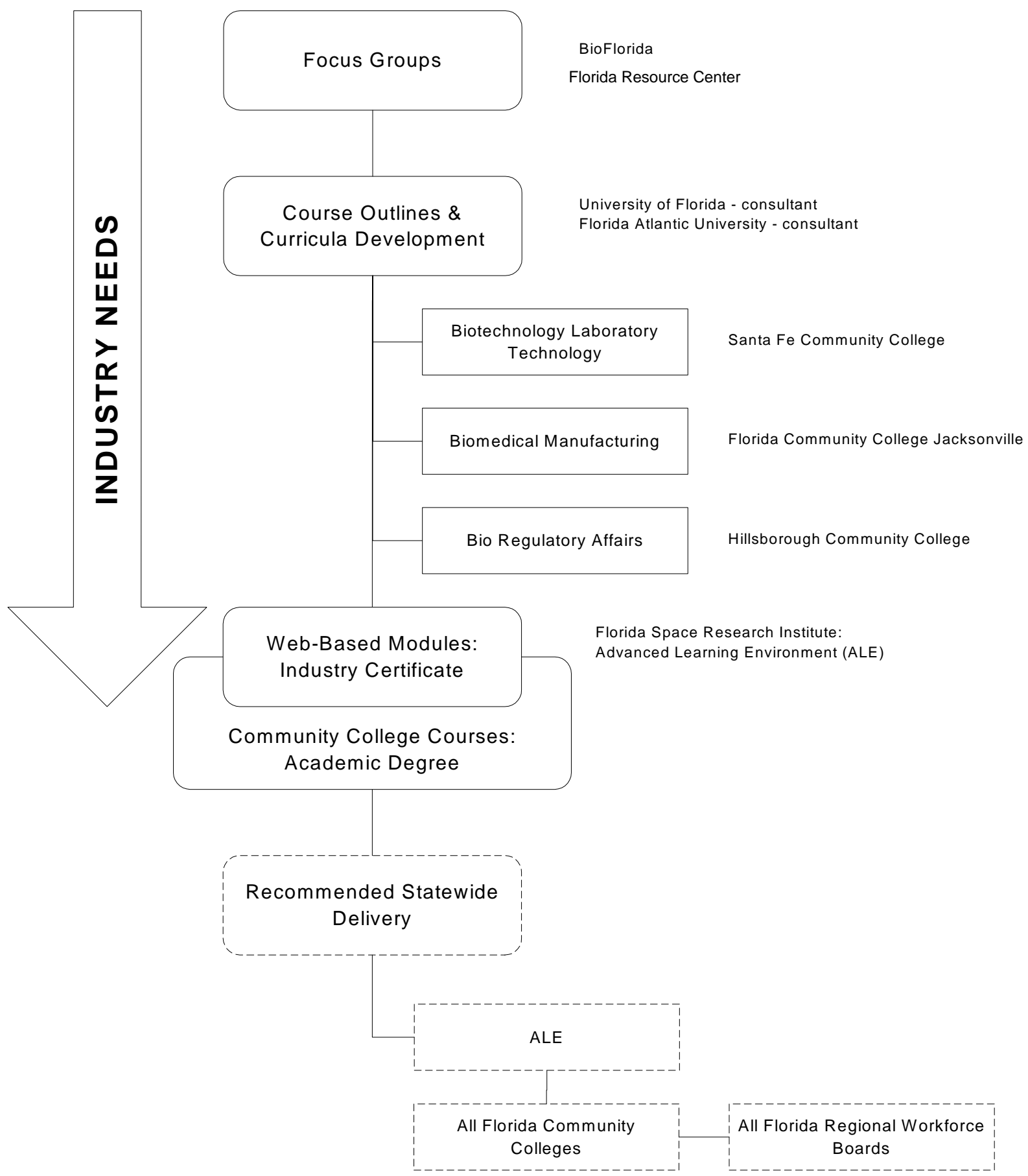

"Proceedings of the 2005 American Society for Engineering Education Annual Conference \& Exposition Copyright $@$ 2005, American Society for Engineering Education” 


\section{Appendix 2. Web-based Module GUI Examples}

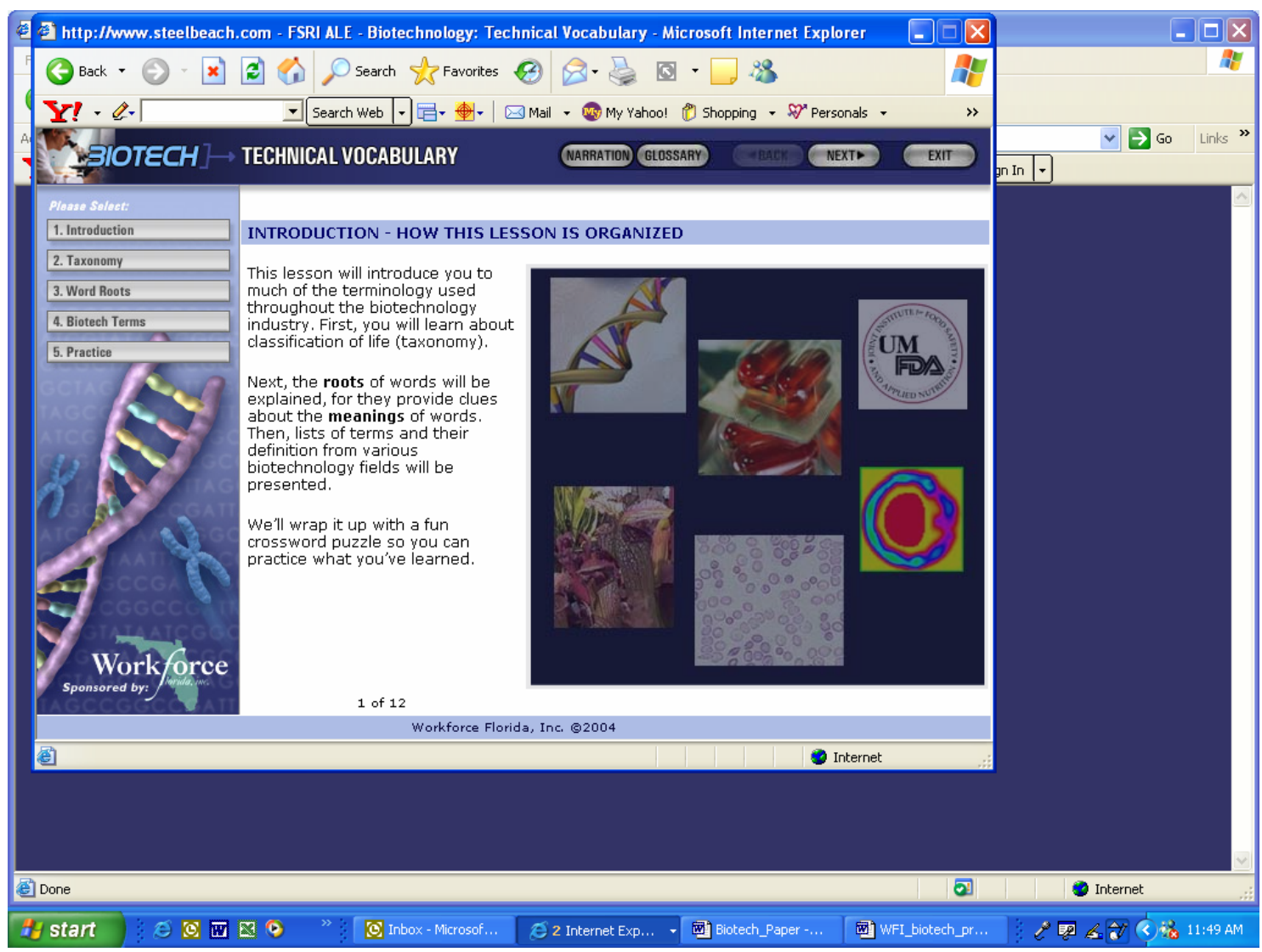

Figure 1. Sample opening screen illustrating screen layout.

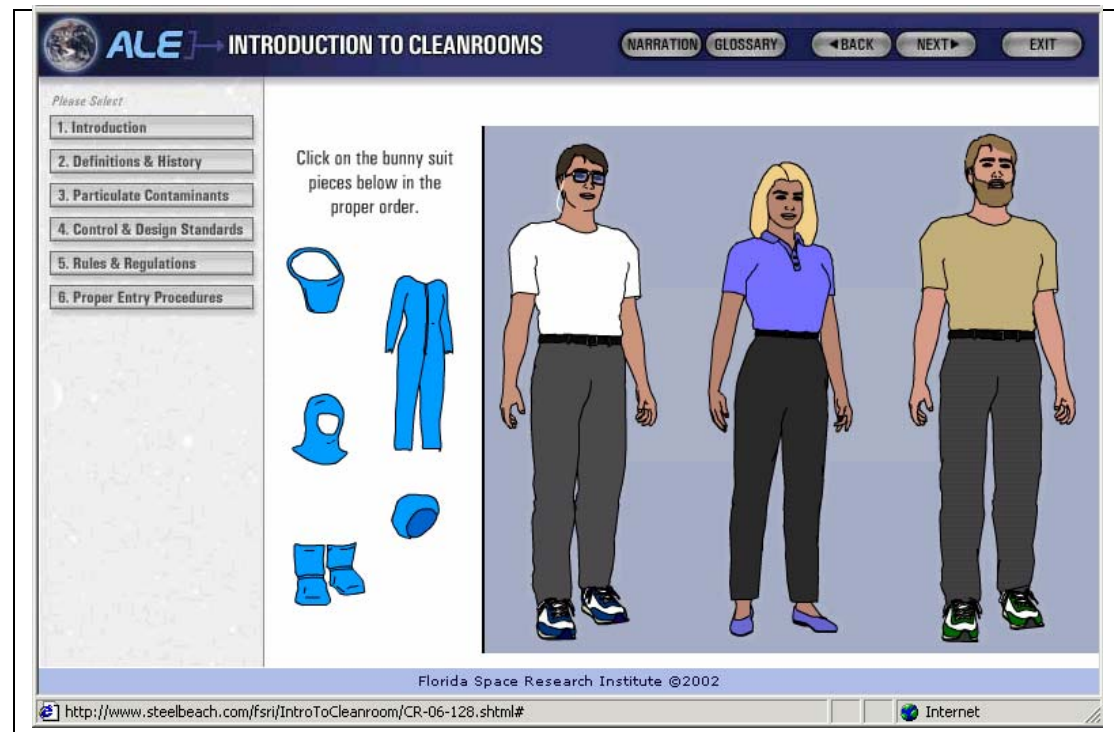

Figure 6: Garmenting of cleanroom personnel is critical and must be done in a specific sequence. This interactive exercise provides a performance based assessment of previously taught material. By clicking on the garments on the left, users virtually dress three aerospace workers in their cleanroom bunny suits. The task must be completed in the proper sequence and remedial feedback is provided for an incorrect attempt. Retention of the information and transfer of knowledge to the job environment are much greater for a performance-based exercise such as this rather than a comparable knowledge-based multiple-choice question.

\section{Figure 2. Sample interactive learning activity in the Cleanroom Module}

